\title{
Pimenta Bueno e uma visão ampla sobre a origem do câncer no início do século XX
}

\author{
Carlos Henrique Fioravanti \\ Doutor em Política Científica e Tecnológica pela Unicamp \\ chfioravanti@gmail.com
}

Como citar este artigo: Fioravanti, Carlos Henrique. "Pimenta Bueno e uma visão ampla sobre a origem do câncer no início do século XX”. Khronos, Revista de História da Ciência, no 7, pp. 184-191. 2019. Disponível em < http://revistas.usp.br/khronos $>$. Acesso em dd/mm/aaaa.

Resumo: O médico paraense Alfredo Leal Pimenta Bueno (1886-?), professor na Faculdade de Medicina de Belo Horizonte, hoje integrada à Universidade Federal de Minas Gerais, apresentou uma visão ampla e original sobre a origem do câncer em uma série de de 19 artigos publicados em 1927 e 1928 na revista Brasil Médico. Integrando química, física, físico-química, bioquímica, genética, citologia, patologia, histologia e fisiologia, ele analisou como o câncer poderia surgir, até mesmo sem qualquer causa conhecida ou aparente, fazer as células perderem suas funções específicas e regredirem ao estado embrionário, quando são pouco diferenciadas entre si, e constituir uma síndrome, que poderia se manifestar localmente, em um órgão ou tecido mais sensível. Por limitações conceituais e instrumentais de sua época, ele não pôde ir além na confirmação ou retificação de suas conclusões, mas muitas de suas conclusões estavam corretas, como o acúmulo de ácidos - a acidose - no interior da célula tumoral. A compreensão aprofundada dos mecanismos hereditários mais profundos só seria possível depois da descoberta da estrutura da molécula de DNA, um dos alvos principais das mutações que favorecem o crescimento de tumores, em 1953.

Palavras-chave: Origem do câncer, história da medicina, história da oncologia, Alfredo Leal Pimenta Bueno. 


\title{
Pimenta Bueno and a broad view on the origin of cancer in the early twentieth century
}

\begin{abstract}
Pará physician Alfredo Leal Pimenta Bueno (1886-?), Professor at the Belo Horizonte Medical School, now part of the Federal University of Minas Gerais, presented a broad and original view of the origin of cancer in a series of 19 articles published in 1927 and 1928 in the magazine Brasil Médico. Integrating chemistry, physics, physicochemical, biochemistry, genetics, cytology, pathology, histology, and physiology, he analyzed how cancer could arise, even without any known or apparent cause, to cause cells to lose their specific and regressive functions. to the embryonic state, when they are poorly differentiated from each other, and constitute a syndrome, which could manifest locally, in a more sensitive organ or tissue. Due to conceptual and instrumental limitations of his day, he could not go further in confirming or correcting his conclusions, but many of his conclusions were correct, such as the accumulation of acids acidosis - within the tumor cell. Further understanding of the deeper hereditary mechanisms would only be possible after the discovery of the structure of the DNA molecule, one of the main targets of mutations that favor tumor growth in 1953.
\end{abstract}

Keywords: origin of cancer, history of medicine, history of oncology, Alfredo Leal Pimenta Bueno.

O câncer é uma doença que independe de uma causa específica e faz as células perderem suas funções específicas e regredirem ao estado embrionário, quando são pouco diferenciadas entre si. É também o resultado do acúmulo de ácidos - uma acidose - no interior da célula, com o consequente aumento da condutibilidade elétrica, que prejudica o funcionamento normal do organismo. O acúmulo de água é uma consequência da acidose nas células tumorais, como nas embrionárias ${ }^{1}$. Encadeando fenômenos biológicos até chegar a conclusões como essas, o médico paraense Alfredo Leal Pimenta Bueno (1886-?), professor de física médica na Faculdade de Medicina de Belo Horizonte, hoje integrada à Universidade Federal de Minas Gerais, apresentou o câncer de modo amplo, examinando-o do ponto de vista da embriologia, da bioquímica e do funcionamento celular, primeiramente em um livro publicado em 1926 e logo depois em uma série de 19 artigos publicados em 1927 e 1928 na revista Brasil Médico. $^{2}$

\footnotetext{
${ }^{1}$ BUENO, Alfredo L. P. Contribuição para o estudo da pathogenia, da physio-pathologia e da therapeutica do cancer, do ponto de vista da doutrina da Trophodynamica Funccional. Brasil Médico, v. 29, p. 719, 1927 e v. 47 , p. 1319.

${ }^{2}$ Encontrei os artigos e o livro nas bibliotecas das faculdades de Medicina e de Saúde Pública da Universidade de São Paulo (USP) em 2012 como parte da pesquisa complementar ao livro A Molécula Mágica.
} 
Numa época em que a prioridade eram a prevenção e o tratamento ${ }^{3}$, Pimenta Bueno foi um dos raros médicos brasileiros a pensar e escrever intensamente sobre as possíveis origens do câncer, em busca de uma visão crítica e integrada dos fenômenos responsáveis por seu surgimento e evolução. Quando necessário, ele não hesitava em questionar os pressupostos conceituais estabelecidos por médicos europeus. Um exemplo de contestação se refere a um trecho de um livro de Brachet (apenas o sobrenome é citado), o Tratado de Embryologia dos Vertebrados, de 1921, uma das raras referências detalhadas:

O eminente Brachet confunde conscientemente organização do protoplasma com sua composição physicochimica; e si isso, á primeira vista, parece uma banalidade, todavia não o é de facto; compreende-se que qualquer modificação na composição physico-chimica da cellula importa, desde logo e consequemente, na modificação da organização do protoplasma4

Os artigos contém longas argumentações e citações em francês ou em italiano de livros sobre embriologia, citologia, fisiologia, física, química e bioquímica, mas seus autores - predominantemente europeus - são citados apenas pelo sobrenome, como Masson, Wolf, Roussy, Bainbridge, Stanley, Ball, Roy, Barbaci, Loeb, Delage, Goldschimidt, Canoy, Lebrun, Van Durme, Rückert, Menetrier, Pantin, Geylard, Portier, Woglom, Ritchie, Gauducheau, Cham-bers, Reiss, Garner, MacDougal, Czaja, Pearsal, Priestlev, Vant'Hoff, Vries, Friedman e Shönfeld. Às vezes os autores são citados com as iniciais dos nomes, como A. Mayer, G. Schaeffer e E.F. Terroine, ou pela nacionalidade, como o italiano Rondoni. Poucas obras são citadas, como o livro Biocbimica de Rondoni e o Biochimica de Lamblino. O médico gaúcho Mário Kroeff é o único brasileiro mencionado; Pimenta Bueno cita uma estatística sobre a transmissão de sífilis que Kroeff apresentou no $1^{\circ}$. Congresso Brasileiro de Higiene, em outubro de $1923^{5}$.

Algumas causas - ou indicações de causas - do câncer eram bem antigas. O médico inglês Sir Percival Pott observou em 1775 que um tipo de câncer de pele era mais comum entre os limpadores de chaminés, mas por 150 anos ninguém fez nada com essa observação. A revolução industrial aumentou a exposição dos trabalhadores a produtos cancerígenos como o alcatrão e piorou a situação ${ }^{6}$. No início do século 20 já se sabia que algumas substâncias químicas causavam câncer, mas as moléculas isoladas que pudessem ter esse efeito não tinham sido identificadas. Em um estudo pioneiro, dois pesquisadores japoneses, Katsusaburo Yamagiwa e Koichi Ichikawa, induziram em 1914 a formação de tumores passando repetidamente alcatrão sobre a pele de orelhas de

${ }^{3}$ PORTUGAL, Olympio. O problema do cancer. O Estado de São Paulo, 11 nov. 1909, p. 1 e TEIXEIRA, Luiz A. O controle do câncer no Brasil na primeira metade do século XX. História, Ciências, Saúde - Manguinhos, v. 17, supl. 1, p. 13-31, 2010.

${ }^{4}$ BUENO, A.L.P. Contribuições... Brasil Médico, v. 49, p. 1286-7, 1927.

${ }^{5}$ BUENO, A.L.P. Contribuições... Brasil Médico, v. 36, p. 924, 1927

${ }^{6}$ WEINSTEIN, Bernard. Current concepts on mechanisms of chemical carcinogenesis. Bulletin of the New York Academy of Medicine, v. 54, n. 4, p. 366-383, 1978. 
coelhos, confirmando as observações de Pott ${ }^{7}$. Só 15 anos depois do experimento dos dois japoneses é que o benzaantraceno foi identificado como o princípio ativo do alcatrão capaz de induzir câncer ${ }^{8}$.

As origens mais profundas do câncer começavam a ser pensadas, principalmente na Europa. O biólogo alemão Theodor Boveri (1862-1915) propôs, em 1914, que alterações no número de cromossomos poderia resultar em células anormais ${ }^{9}$. A busca por um agente causador do câncer mobilizou também os médicos brasileiros. Em 1887, o médico Domingos José Freire Jr., professor de química orgânica na Faculdade de Medicina do Rio de Janeiro, anunciou que tinha descoberto o agente microbiano causador do câncer, a partir de amostras de tumores de pacientes inoculadas em animais, que depois apresentaram tumores similares aos das pessoas. As análises dos tecidos dos animais confirmavam suas conclusões, bastante similares às que o médico alemão Ernest Scheurlen apresentou pouco depois, naquele mesmo ano. Começou então um acirrado debate para ver quem de fato tinha o primeiro a descobrir o tal micróbio, o que garantiria um lugar na história, talvez ao lado de Pasteur e Koch; a descoberta era reivindicada também pelos médicos franceses Gustave Nepveu e Gustave Rappin e pelo italiano Giuseppe Sanarelli ${ }^{10}$. Freire reivindicou a prioridade da descoberta do chamado bacilo do cancro em um comentário publicado em janeiro de 1888 na Gazeta Médica da Babia. Logo depois, em maio de 1888, um artigo da Gazeta Médica da Babia equiparava os resultados de Scheurlen aos de Rappin, obtidos anos antes, e considerava o trabalho de Freire, mas reconhecia que os micróbios eram todos muito parecidos entre si e as evidências ainda não eram suficientes para se concluir algo definitivo ${ }^{11}$.

\section{Um livro e 19 artigos}

As informações sobre a vida pessoal e a trajetória profissional de Pimenta Bueno são escassas. Neto de José Antonio Pimenta Bueno, $1^{\circ}$ marquês de São Vicente (São Paulo, 1803; Rio de Janeiro, 1878) e filho de Joaquim Baptista Pimenta Bueno (Rio de Janeiro, 1850; Belém, 1896) e de Leocádia Pereira Leal Pimenta Buento (Recife, 1859; 1903), Pimenta Bueno nasceu provavelmente em 1886 em Belém, no Pará, para onde seu pai tinha se mudado. ${ }^{12}$ Ele se formou em medicina em 1913 e dois anos depois começou a trabalhar como professor concursado de física médica

\footnotetext{
${ }^{7}$ YAMAGIWA, Katsusaburo e ICHIKAWA, Koichi. Experimental study of the pathogenesis of carcinoma. Cancer Research, v. 3, p. 1-21, 1918

${ }^{8}$ BRANCH, Arnold. Factors in Carcinogenesis. The Canadian Medical Association Journal, v. 41, n. 6, p. 589-90, 1939.

${ }^{9}$ MANCHESTER, Keith L. Theodor Boveri and the origin of malignant tumours. Trends in Cell Biology, v. 5, p. 384-7, 1995 e BIGNOLD, Leon P. et al. Hansemann, Boveri, chromosomes and the gametogenesisrelated theories of tumours. Cell Biology International, v. 30, p. 640-4, 2006.

${ }^{10}$ COSTA, Rui M. P. Entre a teoria parasitária e a oncologia experimental: uma proposta de sistematização da ciência oncológica em Portugal, 1889-1945. História, Ciências, Saúde - Manguinhos, v. 19, n. 2, p. 409-429, 2012 e BENCHIMOL, Jaime L. Domingos José Freire e os primórdios da bacteriologia no Brasil. História, Ciências, Saúde - Manguinhos, v. 2, n. 1, p. 67-98, 1995.

${ }^{11}$ FREIRE, Domingos. Reclamação da prioridade da descoberta do bacilo do cancro. Gazeta Médica da Babia, v. 19, n. 7, p. 331-333, 1888 e O micróbio...1888.

12 Em uma convocatória da Junta Permanente de Alistamento Militar do Distrito Federal publicada no Diário Oficial da União (DOU) de 3 de junho de 1930, o nome de Pimenta Bueno consta na Classe 1886,
} 
na Faculdade de Medicina de Belo Horizonte, hoje integrada à Universidade Federal de Minas Gerais. Um dos sinais de sua crescente inquietação intelectual é o aparelho que ele criou para medir pressão arterial, um Sphygmo-oscilometro mano-metrico, do qual requisitou uma patente em 1922. O médico e escritor mineiro Pedro Nava lembrava-se que Pimenta Bueno, seu professor no curso de medicina, "falava bem, numa voz clara e era senhor de dicção invejável”13.

Seus textos científicos preservaram a retórica da sala de aula. Em seu livro de 1926, Pimenta Bueno apresentava o resultado de dez anos de estudos e anunciava: "Eu pude chegar a uma serie de conclusões originaes, tendo por base principios geraes de physiologia normal e pathologica” (BUENO, 1926, p. 5-6). Eram as correlações hemáulicas, expressão que ele havia criado para designar as reações orgânicas, vistas como um conjunto de atos fisiológicos sinérgicos, decorrentes das variações da circulação sanguínea em cada tecido, em resposta a estímulos nervosos ou hormonais - a expressão era também o título do livro de 76 páginas, impresso no Rio de Janeiro, mas não há sinais de que tenha sido adotada por outros além dele próprio.

Pimenta Bueno via qualquer atividade do organismo como "um phenomeno de energetica", que implicava um desequilíbrio de energia ou "transformação de um certo potencial em energia actual ou dynamica, portanto em uma degradação energética"; o material energético seriam as substâncias nutritivas que abastecem o organismo para necessidades imediatas ou futuras; de modo mais amplo, o equilíbrio do organismo dependeria da circulação sanguínea, que transporta os nutrientes. Para ele, os fenômenos orgânicos seguiam um princípio da termodinâmica, o da conservação de energia: a quantidade de energia que cir-cula em um sistema de corpos em equilíbrio como o organismo é constantemente a mesma; a célula não poderia criar nem destruir energia, era apenas um transformador de energia ${ }^{14}$.

O livro de 1926 observa que os tumores lançam na circulação sanguínea os resíduos de seu metabolismo, que aceleram a atividade celular, culminando na caquexia, a perda involuntária de peso e de ânimo que caracteriza o câncer. E apresentava as bases conceituais que ele adotou para entender o surgimento, a evolução e a expressão de tumores nos 18 artigos publicados em 1927 e 1928 na Brasil Médico sob o título de Contribuição para o estudo da pathogenia, da physio-pathologia $e$ da therapeutica do cancer, do ponto de vista da doutrina da Tropho-dynamica Funccional, que somam 128 páginas. ${ }^{15}$

indicando que seria esse seu ano de nascimento, já que os homens no Brasil são convocados aos 18 anos (DOU, 1930). Uma nota no jornal O Pará indica que ele passou a infância em Belém, onde provavelmente nasceu, já que seus pais viviam lá: “DESASTRE. Um filho da sra. Dona Leocadia Pimenta Bueno, de nome Alfredo, estando a brincar em companhia de outros meninos, com bombas, uma rebentou-lhe no rosto, ferindo-lhe o olho esquerdo. É grave o seu estado" (Desastre, 1899).

13 NAVA, Pedro. Chão de ferro, São Paulo: Ateliê Editorial, 2001, p. 334.

14 BUENO, A.L.P. Correlações Hemaulicas (Do ponto de vista da doutrina da Tropho-dynamica funccional). Rio de Janeiro, Livraria Editora Leite Ribeiro Freitas Bastos, Spicer \& Cia, 1926, p. 8-9 e 28.

${ }_{15}$ Um dos artigos de 1928, que remete aos anteriores, intitula-se "Sobre Certos Phenomenos Moleculares de Contacto Solido-Liquido". Brasil Médico, v. 47, p. 1317-1323. 
Um rigor crítico e às vezes cáustico transborda de seus textos. No primeiro artigo, ao apresentar seu plano de entender as origens e a evolução do câncer, ele incitava médicos e cientistas a serem mais ousados, alertando-os que não bastava acumular fatos, produzir tumores em animais de laboratório, escrever "enxertos de volume igual ao de um elephante" e saber diferenciar os tipos de tumores: "É necessário poder animar os factos recolhidos pela observação com o divino sôpro da sabedoria, construindo sobre elles as leis e os principios que, afinal, são a crystallização de nosso proprio saber sobre as cousas naturaes..." Pimenta Bueno reconhecia que a medicina ainda não contava com todos os conceitos necessários para examinar as origens do câncer, mas se sentia à vontade para enfrentar esse desafio exatamente por pensar de modo independente: “jamais reverenciei as ideias e os conceitos pela sua origem; jamais bajulei servilmente, na inconsistencia da preguiça ou da inercia intellectual, nem os maioraes da Sciencia nem as conclusões alheias, fossem ellas de que origem fossem..." Em seguida ele lembrava "tambem os outros podem cair em erro..."16.

Seu propósito inicial era entender como os agentes biológicos (microrganismos), químicos, físicos ou ambientais atuavam no organismo de modo a acionar os mecanismos que conduziriam os tecidos ao câncer. Vendo que não havia uma causa específica, ele relatou: "Os canceres independem do agente provocador". O câncer, ele concluiu, poderia surgir até mesmo sem qualquer causa conhecida ou aparente ${ }^{17}$, nesse ponto concordando com a noção de que poderia haver uma predisposição do organismo, a chamada diátese. Ele enfatizava o uso integrado dos conceitos de química, física, físico-química, bioquímica, biologia, patologia, fisiologia e histologia para se ter uma visão ampla, e não unilateral, do câncer. Sua atenção focava-se ora no funcionamento celular, ora em todo o organismo.

Pimenta Bueno reconhecia que, nas células tumorais, os cromossomos estavam desorganizados e apresentavam uma atividade mais intensa que nas células normais ${ }^{18}$. Uma relação entre câncer e hereditariedade começava a emergir na Europa. Em seu tratado sobre tumores (de 1866, em dois volumes), o médico francês Paul Broca refez o percurso histórico do conceito de câncer - desde o médico romano Cláudio Galeno, que associava o surgimento de tumores ao estado de melancolia - e apresentava sua hipótese de que os tumores poderiam se formar muitos anos antes de os primeiros sintomas se manifestarem. Segundo Broca, a predisposição do organismo para certas doenças poderia produzir o primeiro câncer, que produz infecção, que por sua vez produz os tumores secundários, caquexia (profundo abatimento) e morte. Para mostrar a possibilidade de o câncer ser transmitido em uma mesma família, um fenômeno que muitos médicos consideravam apenas coincidência, Broca listava as 16 mortes causadas por câncer de mama em cinco gerações da família de sua esposa entre 1788 e 1856. O conceito era importante, mas o exemplo não: os

${ }_{16}$ BUENO, Alfredo L. P. Contribuição para o estudo da pathogenia, da physio-pathologia e da therapeutica do cancer, do ponto de vista da doutrina da Trophodynamica Funccional. Brasil Médico, v. 15, p. 332, 1927

17 Idem, p. 334-5.

18 Idem, p. 439. 
casos não haviam sido documentados, o câncer de mama é relativamente comum - seu aparecimento em uma linhagem familiar pode ser ao acaso - e os portadores de genes causadores de câncer de mama podem nunca desenvolver a doença, dificultando as análises ${ }^{19}$. Pouco depois, no Rio de Janeiro, o médico Hilário de Gouvêa ofereceu uma evidência mais consistente de uma causa genética hereditária do câncer ao rastrear e identificar uma forma rara de câncer hereditário de retina chamada retinoblastoma em uma mesma família ${ }^{20}$.

Nos artigos seguintes, Pimenta Bueno examinou o câncer como uma síndrome, que poderia se manifestar localmente, em um órgão ou tecido mais sensível, de modo espontâneo ou induzido, por exemplo, por uma irritação. O crescimento das células tumorais dependeria do metabolismo dos órgãos e dos sentidos, mais exatamente do excesso de nutrição local, a chamada hiperemia, o aumento da quantidade de sangue em um tecido ${ }^{21}$. Ao ver que doenças como a catarata, a perda da transparência do cristalino do olho, poderiam ser causadas pelos mesmos agentes físicos, como o calor, raios ultravioleta ou raios X, ele concluiu que o câncer resultava da destruição de proteínas celulares, "um processo verdadeiramente lytico", como ele dizia, causado pela hiperidratação dos tecidos (de fato, como se verificou muitas décadas depois, o crescimento das células tumorais implica, de fato, a destruição das células normais, essencialmente por espalhamento de substâncias ácidas e de fatores de contenção de crescimento das células sadias vizinhas às tumorais, aparentemente não por acúmulo de água). A partir desse raciocínio, Pimenta Bueno chamou a catarata de câncer do cristalino, onde até aquele momento ainda não havia sido identificado nenhum outro tipo de tumor ${ }^{22}$, mas hoje se sabe que a catarata não está ligada ao câncer.

\section{Conclusões}

Pimenta Bueno desenvolveu uma visão aprofundada, original e abrangente sobre a origem do câncer, que merece ser detidamente examinado por historiadores da ciência, médicos e cientistas. Por limitações conceituais e instrumentais de sua época, ele não pôde ir além na confirmação ou retificação de suas conclusões, mas muitas de suas conclusões estavam corretas. O bioquímico alemão Otto Warburg, embora não tenha sido mencionado nos artigos da Brasil Médico, tinha descrito em 1924 os mecanismos próprios de produção de energia (glicose) adotados pelas células tumorais, resultando em resíduos ácidos que, ao se espalharem, prejudicam as células sa$\operatorname{dias}^{23}$.

\footnotetext{
${ }^{19}$ BROCA, Paul P. Traité des tumeurs. 1st ed. Paris: Asselin; 1866 e KRUSH, Anne J. Contributions of Pierre Paul Broca to Cancer Genetics. Transactions of the Nebraska Academy of Sciences and Affiliated Societies. Paper 316, 1979.

20 MUKHERJEE, Siddartha. Imperador de todos os males - Uma biografia do câncer. Cia. das Letras, SP, 2012 e MONTEIRO, Álvaro N. e WAIZBORT, Ricardo. The accidental cancer geneticist: Hilário de Gouvea and Heredity Retinoblastoma. Cancer Biology and Therapy, v. 6, n. 5, p. 811-3, 2007.

${ }^{21}$ BUENO, A.L.P. Contribuições.... Brasil Médico, v. 18, p. 442, 1927.

22 BUENO, A.L.P. Contribuições.... Brasil Médico, v. 20, p. 468, 1927.

23 WARBURG, Otto et al. Ueber den Stoffwechsel der Tumoren; Biochemische Zeitschrift, Vol. 152, pp. 319344, 1924 e WARBURG, Otto. On the Origin of Cancer Cells. Science, v. 123, n. 3191, p. 309-14, 1956.
} 
Em seu livro de 1935 sobre câncer, o médico paulista Antonio Prudente, responsável pela criação do Hospital do Câncer de São Paulo, um dos primeiros centros de atendimento nessa área, em funcionamento desde 1953 na capital paulista, também mencionou a acidose como uma característica dos tecidos tomados por células tumorais ${ }^{24}$. Nos Estados Unidos, Robert Gatenby apresentou em 1995 sua hipótese de que a intensificação da síntese de glicose em células tumorais poderia gerar acidez - e, por causa do excesso de íons hidrogênio $\left(\mathrm{H}^{+}\right)$, os tumores se tornariam eletricamente positivos ${ }^{25}$. A acidez poderia modificar o equilíbrio bioquímico do tumor, selecionar as células tumorais, deixando apenas as mais resistentes, eliminar as células sadias próximas e permitir às células tumorais migrarem para outras regiões do organismo.

A compreensão dos mecanismos genéticos e hereditários do câncer só seria possível depois da descoberta da estrutura da molécula de DNA, um dos alvos principais das mutações que favorecem o crescimento de tumores, em 1953.

24 PRUDENTE, A. O câncer - precisa ser combatido. São Paulo, Calvino Filho, 1935 e IORI, Cristina e NASSIF, Eliana L. Antonio Prudente: Turning Dreams into Reality. Applied Cancer Research, v. 25, n. 2, p. 9310, 2005.

${ }^{25}$ GATENBY, Robert. The potential role of transformation-induced metabolic changes in tumor-host interaction. Cancer Research, v. 55, n. 18, p. 4151-6, 1995. 